\title{
The South African paediatric tumour registry - 25 years of activity
}

To the Editor: We appreciate Drs Stefan and Stones highlighting the value of cancer registries. ${ }^{1}$ Establishing a comprehensive population-based cancer registry in South Africa is most important and long overdue. This does not preclude specialised registries, provided that all cancers are reported to the main, statutory registry. Best practice is inclusive reporting of all cancers to a single registry for all age groups, which enables national trends to be described for the entire South African population, including rural areas. Recently, the National Cancer Registry (NCR) has received renewed support from the National Department of Health and the NHLS, as they have increased the focus of health services towards the expanding chronic disease epidemics, which has also motivated the NCR to initiate a hospital-based registry in Ekurhuleni (Gauteng Province) to pilot reporting on the new forms.

The new cancer regulations (Act No. 61 of 2006 No. R.380) require every healthcare provider who diagnoses or treats cancer in a patient to report to the NCR using the statutory form. ${ }^{2}$ Duplicates are valuable to provide complete information and to ensure that no cases are missed. Overall compliance, 14 months after gazetting, has been slow and at times incomplete. Some respondents, for example, did not complete the risk factor section. Compliance by paediatric oncologists has been good. This kind of comprehensive information can be used for research and to assist planning for increased provision of diagnostic, preventive and treatment services.

Improved collaboration between various cancer service providers, researchers and other interest groups in South Africa is pivotal for enhancing cancer services, facilitating much-needed research into cancer risks, incidence and survival, and providing increased capacity for prevention and education. NCR data are available on formal request. For NCR statistics from 2000 - 2004, including age-specific rates and information on the new cancer regulations, access the National Institute for Occupational Health website (www.nioh.ac.za; publications; cancer statistics) or by directly contacting the National Cancer Registry.

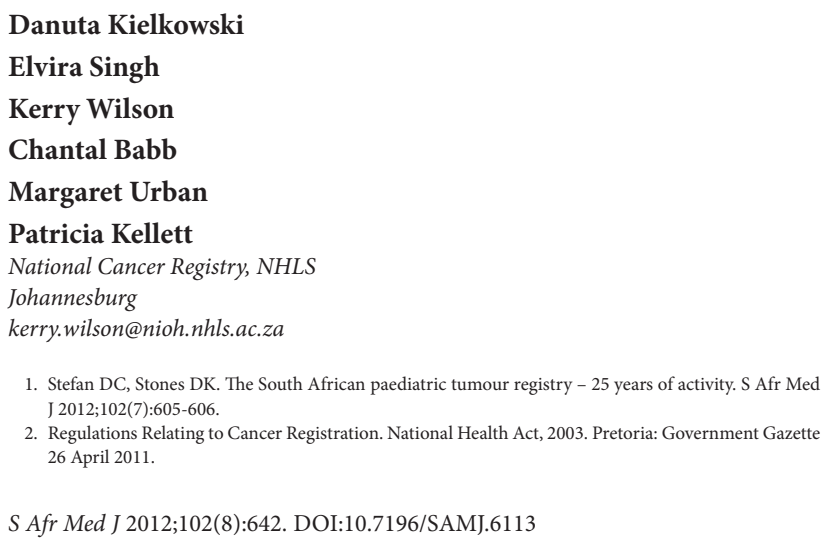

S Afr Med J 2012;102(8):642. DOI:10.7196/SAMJ.6113 